\title{
Detection of coconut (Cocos nucivera) sugar adulteration in palm (Arenga pinnata Merrill) sugar by Fourier Transform Infrared (FT-IR) Spectroscopy
}

\author{
Roosmayanti, F., Rismiwindira, K. and *Masithoh, R.E. \\ Department of Agricultural and Biosystems Engineering, Faculty of Agricultural Technology, Universitas \\ Gadjah Mada, Yogyakarta, Indonesia 55281
}

\author{
Article history: \\ Received: 7 December 2020 \\ Received in revised form: 16 \\ April 2021 \\ Accepted: 10 June 2021 \\ Available Online: 20 June \\ 2021
}

Keywords:

Adulteration,

Coconut Sugar,

Palm Sugar,

FT-IR,

PCA,

PLSR

DOI:

https://doi.org/10.26656/fr.2017.5(S2).013

\begin{abstract}
Palm sugar which is also named brown sugar is powdered sugar produced from palm extract. Due to the high price of palm sugar, its contamination of materials that are cheap or low quality is inevitable. Usually, adulteration detection is done by conventional methods such as HPLC, TLC, or NMR which are time-consuming and require high-priced equipment, thus impractical for routine and large sample analysis. The aim of this research was to detect adulteration in palm sugar using Fourier Transform Infrared (FT-IR) spectroscopy. The samples used in this study were palm sugar as the main ingredient and coconut sugar as the adulterant. Two chemometric methods namely principal component analysis (PCA) and partial least squares regression (PLSR) were used for analysis. The absorbance data were taken at wavenumber $4000-650 \mathrm{~cm}^{-1}$. Several concentrations of coconut sugar as an adulterant ranging from 0 to $100 \%$ were added to palm sugar. A total of 110 spectra of both pure and adulterated palm sugar samples were divided into two groups, i.e. 73 samples for developing calibration model and 37 samples for developing prediction model. The spectral obtained were pre-processed and analyzed using The Unscrambler $\mathrm{X}$ version 10.4 a total of six pre-processing methods were used, i.e., Normalization, Standard Normal Variate (SNV), Multiplicative Scatter Correction (MSC), and Baseline. Results showed that PCA was able to classify palm sugar based on adulterant concentrations. PLSR calibration model with a coefficient of determination $\left(\mathrm{Rc}^{2}\right)$ of 0.94 and root mean square error of calibration (RMSEC) of $8 \%$ was obtained by applying the MSC method. The model was able to predict coconut sugar adulteration in palm sugar with $\mathrm{Rp}^{2}$ of 0.89 and root mean square error of prediction (RMSEP) of $10.68 \%$. The results confirmed the potential of FT-IR spectroscopy for detecting adulteration in palm sugar.
\end{abstract}

\section{Introduction}

Palm sugar or brown sugar (gula semut) is a popular name for powdered or crystalline brown sugar made from palmae family, such as aren (Arenga pinnata Merrill), coconut (Cocos nucivera), or siwalan (Borassus flabellifer L.) extract. Indonesia is one of the ten biggest palm sugar exporter countries in the world with a market share of $8.7 \%$ (Direktorat Jenderal Pengembangan Ekspor Nasional, 2017). Recently, people have started to use palm sugar products in their diet to alternate conventional refined sugar. Palm sugar contains higher fructose and fructose but lower sucrose than conventional refined cane sugar (Srikaeo et al., 2019). In addition, palm sugar from Arenga pinnata has glycemic index (GI) of $40 \pm 3$ (Merr and Haagen, 2014) while cane sugar has GI of 91 (Srikaeo et al., 2019).
The price of brown sugar in the market made from Arenga pinnata (in this paper is called palm sugar) is more expensive than brown sugar made from coconut (Cocos nucivera). Due to the high price of palm sugar, it is possible to contaminated with coconut sugar which is cheaper but has similar color and texture thus difficult to differentiate using naked eyes. Usually, adulteration or authentication is detected by conventional methods such as HPLC (Domingues et al., 2014), chromatographic et al., 2016), or NMR (Bergana et al., 2019) which require long time analysis and high-priced equipment, thus not practical for large samples and routine analysis.

Spectroscopy techniques at near-infrared (NIR) and mid-infrared (MIR) regions have been popular for quality and quantitative food analysis. MIR spectroscopy at $4000-400 \mathrm{~cm}^{-1}$ provides a sharper and larger intensity 
of chemical information compared to NIR since it describes the fundamental vibrations rather than the overtones and combination bands measured in NIR region (Lohumi et al., 2015). Fourier Transform Infrared (FT-IR) spectroscopy have been used for classification or identification, such as classification of tuber powder having similar color (Masithoh et al., 2020), quantification sugar in honey (Anjos et al., 2015), or identification of anthocyanin (Amanah et al., 2020). Several studies also reported the possibility of FT-IR for detecting the presence of adulterants of corn starch in onion powder (Lohumi et al., 2014), common wheat in durum wheat pasta (De Girolamo et al., 2020), or adulteration in black pepper (Wilde et al., 2019). However, studies that reported the application of FT-IR for detecting adulteration in palm sugar is not available; therefore, it will be reported in this study.

This research aimed to study the potential of the FTIR spectroscopy method to detect adulteration of brown sugar made of coconut sap in palm sugar made from Arenga pinnata sap. Chemometric methods namely principal component analysis (PCA) and partial least squares regression (PLSR) were used for analysis. In this study, PCA was used to classify various concentration of adulterant in palm sugar and PLRS was used to predict the adulterant concentration in palm sugar using FT-IR absorbance.

\section{Materials and methods}

\subsection{Sample preparation}

Palm sugar and coconut sugar were obtained from several local markets in Indonesia. Coconut sugar which had a cheaper price but similar color to palm sugar was used as the adulterant, while palm sugar was used as the adulterated samples. Several concentrations of coconut sugars ranging from 0 to $100 \%$ were added to palm sugar making the final concentrations of $50 \mathrm{~g}$ scaled using an analytical balance (Ohaus Scout Pro SPS202F). The sample arrangement was set as shown in Table 1.

Table 1. Percentage and weight combination of coconut sugar and palm sugar used as samples

\begin{tabular}{ccccc}
\hline \multirow{2}{*}{ Class } & \multicolumn{2}{c}{ Coconut sugar } & \multicolumn{2}{c}{ Palm sugar } \\
\cline { 2 - 5 } & $\%$ & Weight $(\mathrm{g})$ & $\%$ & Weight $(\mathrm{g})$ \\
\hline $0 \%$ & 0 & 0 & 100 & 50 \\
$10 \%$ & 10 & 5 & 90 & 45 \\
$20 \%$ & 20 & 10 & 80 & 40 \\
$30 \%$ & 30 & 15 & 70 & 35 \\
$40 \%$ & 40 & 20 & 60 & 30 \\
$50 \%$ & 50 & 25 & 50 & 25 \\
$60 \%$ & 60 & 30 & 40 & 20 \\
$70 \%$ & 70 & 35 & 30 & 15 \\
$80 \%$ & 80 & 40 & 20 & 10 \\
$90 \%$ & 90 & 45 & 10 & 5 \\
$100 \%$ & 100 & 50 & 0 & 0 \\
\hline
\end{tabular}

eISSN: $2550-2166$
Although coconut and palm sugar were purchased dry, the mixed sugar samples were dried at $65-70^{\circ} \mathrm{C}$ for $12 \mathrm{hrs}$ in a dehydrator to remove excess water as infrared spectroscopy are significantly affected by moisture content. In this study, the water content of coconut sugar and palm sugars were $1.2 \%$ and $0.7 \%$, respectively. After drying, the samples were sieved manually with an 80mesh sieve $(0.18 \mathrm{~mm}$; ASTM Standard $)$ in order to obtain uniform size samples. Samples that did not pass 80-mesh were ground and sieved to pass 80-mesh. Each combination was placed in a closed bottle and mixed for 2 mins. A total of ten samples of each concentration combination were used making the total of 110 samples. The samples were put into the desiccator (Normax ISO 13130) and stored at room temperature before spectra acquisition.

\subsection{Spectra acquisition}

FT-IR spectra scanning were performed with a Thermo Nicolet iS10 (Thermo Nicolet Corp., Madison, WI), equipped with a $\mathrm{ZnSe}$ crystal plate. The spectra were measured in the mid-infrared area in absorbance mode at a wavelength of $4000-650 \mathrm{~cm}^{-1}$. The sampling method used was attenuated total reflectance (ATR) using a deuterated triglycine sulfate (DTGS) detector, controlled by OMNIC software. A background scan was performed on each sample scan with an empty sample plate. The ATR crystal plate and pointed tip were cleaned to remove interference from the previous sample using ethanol. Spectra were acquired by placing a $30 \mathrm{mg}$ sample on a diamond crystal plate and clamped with a pointed tip (Figure 1). Reflectance spectra of 110 samples were collected using $4 \mathrm{~cm}^{-1}$ intervals resulted in total of 6950 variables.

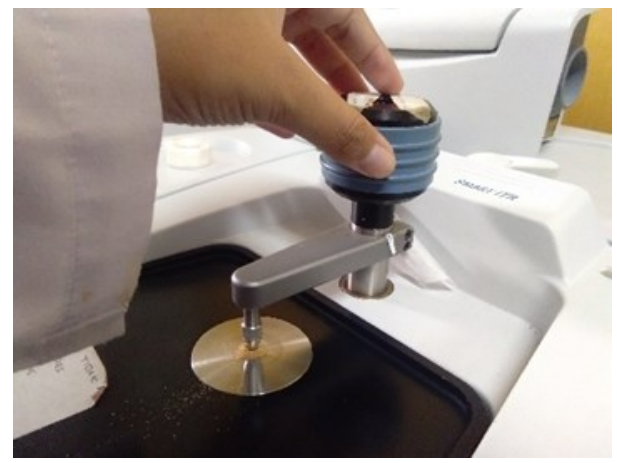

Figure 1. Spectra acquisition using Thermo Nicolet Is10

\subsection{Spectral data analysis}

Spectra collection was obtained using the OMNIC Software which was then converted into an Excel $\mathbb{R}$ file for further analysis. The raw data obtained from the IR instrument were in reflectance values which were then converted into absorbance values. The absorbance data was then imported to the Unscrambler X version 10.4 
(CAMO Software AS, Oslo, Norway) for spectra pretreatment and multivariate analysis, i.e. PCA and PLSR analysis. Spectroscopy contains large data variables but only several variables are important to describe chemical substances. PCA can be used to reduce dimensions to explain the most important features of the data set. Prediction of concentrations of adulteration in the palm sugar samples is developed based on spectra data using PLSR.

The whole data set (110 samples) was divided into two sets, i.e. a calibration set consisting of 73 samples and a prediction set consisting of 37 samples. Due to possible noise in the spectra resulting from light scattering, particle size, and instrument, raw spectra must be corrected by applying several spectra preprocessing methods (Lohumi et al., 2014). In this study, FT-IR spectral data were processed using Normalization, Standard Normal Variate (SNV), Multiplicative Scatter Correction (MSC), and Baseline.

\section{Results and discussion}

\subsection{Interpretation of Spectra}

Figure 2 illustrates the original and SNV processedspectra of pure and palm sugar adulterated coconut sugar at infrared region $\left(4000-650 \mathrm{~cm}^{-1}\right)$ at which spectra are divided into two major regions, i.e. below and above $1500 \mathrm{~cm}^{-1}$ showing fingerprint and functional group region, respectively. Molecular vibrations located in the infrared region but at the region below $1500 \mathrm{~cm}^{-1}$, sharp and narrow spectra can be observed, while region above $1500 \mathrm{~cm}^{-1}$ reveals wide and fewer spectra.

It can be seen in Figure 2a the original spectra show similar trends for all spectra which is difficult to determine which spectra it belongs to which concentration. After applying the SNV method to original spectra, spectra can be differentiated according to adulterant concentration at wavebands as shown in

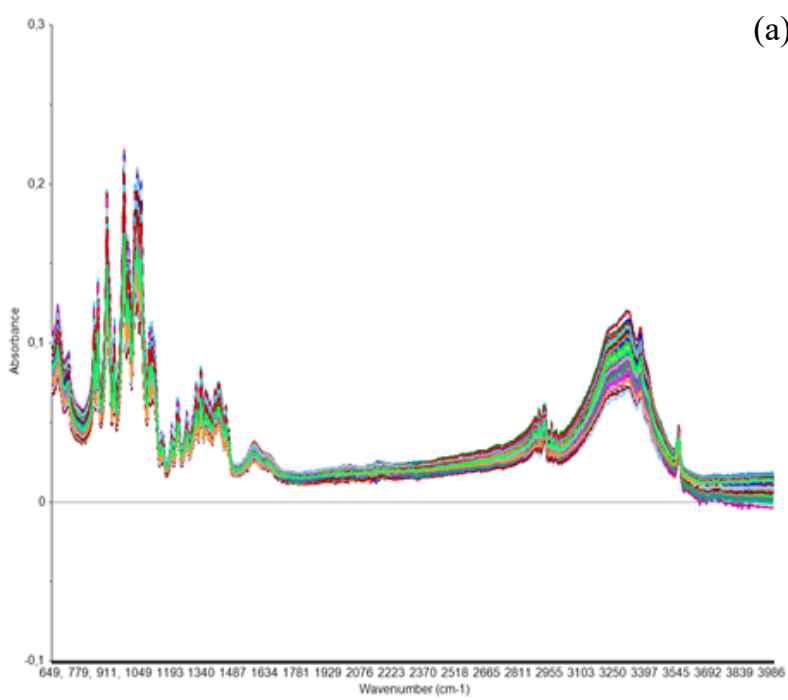

(a)
Figure2b Those spectra revealed at $1500-700 \mathrm{~cm}^{-1}$ are functional groups which corresponded to $\mathrm{C}=\mathrm{C}$ (Amanah et al., 2020), C-H, O-H, C-O (Musingarabwi et al., 2016) and C-N (Masithoh et al., 2020), 2300-1700 $\mathrm{cm}^{-1}$ corresponding to the vibration of $\mathrm{C}=\mathrm{C}, \mathrm{C}=\mathrm{O}, \mathrm{C} \equiv \mathrm{C}$, and $\mathrm{C} \equiv \mathrm{N}$, and $3000-2800 \mathrm{~cm}^{-1}$ corresponding to the vibration of $-\mathrm{C}-\mathrm{H}$. Broad and high absorption at $3300-3200 \mathrm{~cm}^{-1}$ which are vibrations of $\mathrm{O}-\mathrm{H}$ might be associated with water content of samples (Anjos et al., 2015).

\subsection{Principle Component Analysis (PCA)}

PCA is an exploratory method used to study the relations among data variables, to cluster the samples, and to visualize data in a low dimension (Szymańska et al., 2015). As shown in Figure 3a, PCA using PC-6 and PC-7 cannot differentiate clearly palm sugar based on adulteration concentration, but pure and low concentrations of adulteration palm sugar are in the negative axis of PC-6. By using SNV pre-processing spectra and clustering level of adulteration concentration into 3 groups instead of 11 groups, more distinct classifications are observed by using PC-2 and PC-6. In Figure $3 \mathrm{~b}$, although some samples are still grouped together, pure $(0 \%)$ and low-level adulteration $(10-20 \%)$ palm sugar were observed at the positive axis of PC-2, medium-level adulteration (30-60\%) were located at the negative axis of PC-6, and high-level of adulteration (70$100 \%$ ) were at the positive axis of PC-6.

Figure 4 shows the high loadings at 1050 and 1150 $\mathrm{cm}^{-1}$ assigned to the combination of $\mathrm{C}-\mathrm{C}-\mathrm{H}$ and $\mathrm{O}-\mathrm{C}-\mathrm{H}$ as well as $\mathrm{C}-\mathrm{O}-\mathrm{C}$ associated with sugar molecules (Zhou et al., 2020). Sugar content in palm sugar mainly sucrose as well as glucose and fructose but in lower concentrations (Srikaeo et al., 2019). Although spectra of individual sugars are unable to specifically determine, samples on the PC-2 positive axis belong to pure and low -level adulterated palm sugar which have higher sucrose compared to coconut sugar. The interpretation is similar

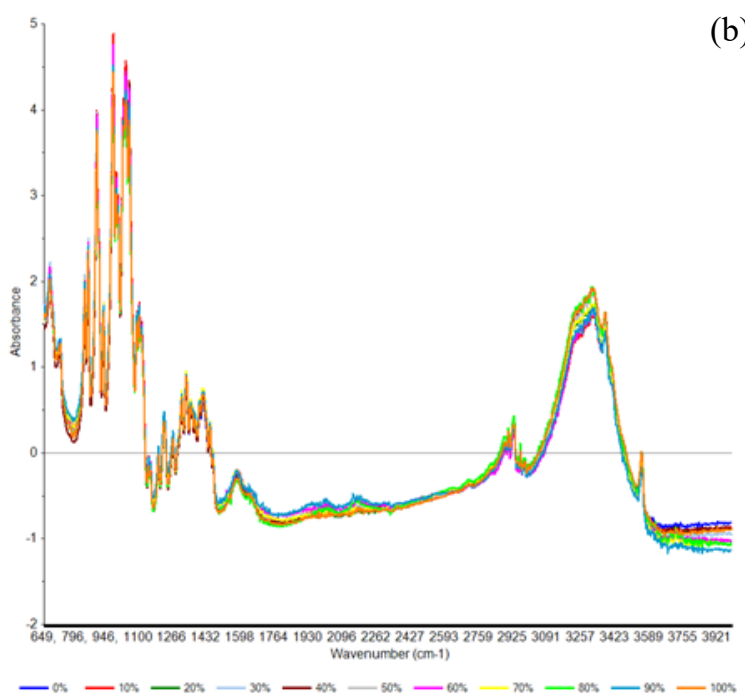

(b)

Figure 2. (a) Original and (b) SNV Spectra of different concentration of pure and adulterated palm sugar 


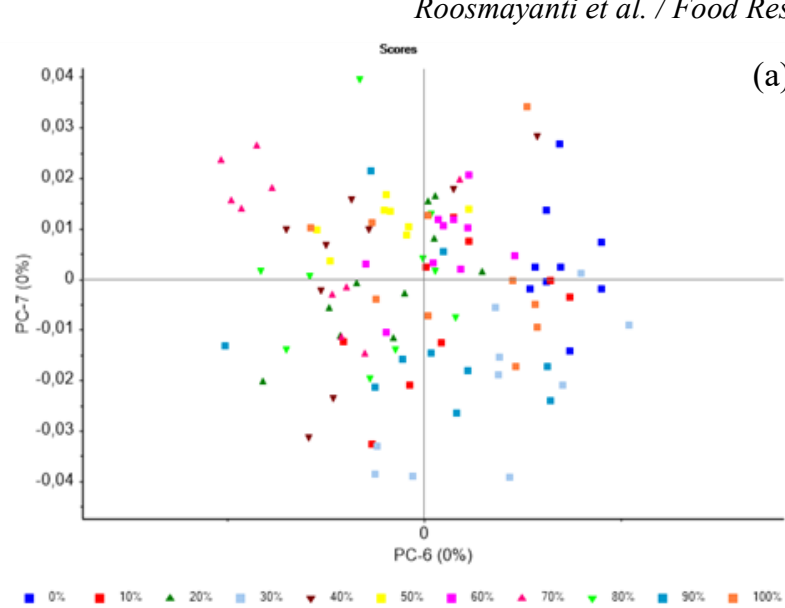

(a)

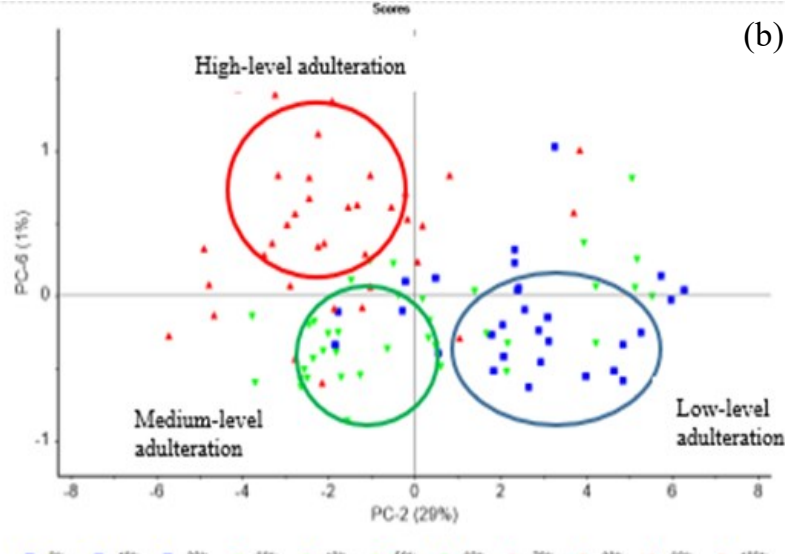

Figure 3. PCA of (a) Original and (b) SNV Pre-processed of FT-IR spectra showing clustering based on adulteration level to findings reported by (Asghar et al., 2020) in which compared to palm juice, coconut sap has lower sucrose but higher fructose and glucose.

Peaks at 1614 and $3280 \mathrm{~cm}^{-1}$ assigned to $\mathrm{OH}$ deformation and stretch of water (Anjos et al., 2015) which affects sugar $\mathrm{OH}$ absorption (Bahrami et al., 2020). In this study, coconut sugar has higher water than palm sugar which is reflected from Figure 4 in which samples with medium and high-level adulteration including pure coconut sugar located at the negative axis of PC-2 showed by absorbance at $3280 \mathrm{~cm}^{-1}$.

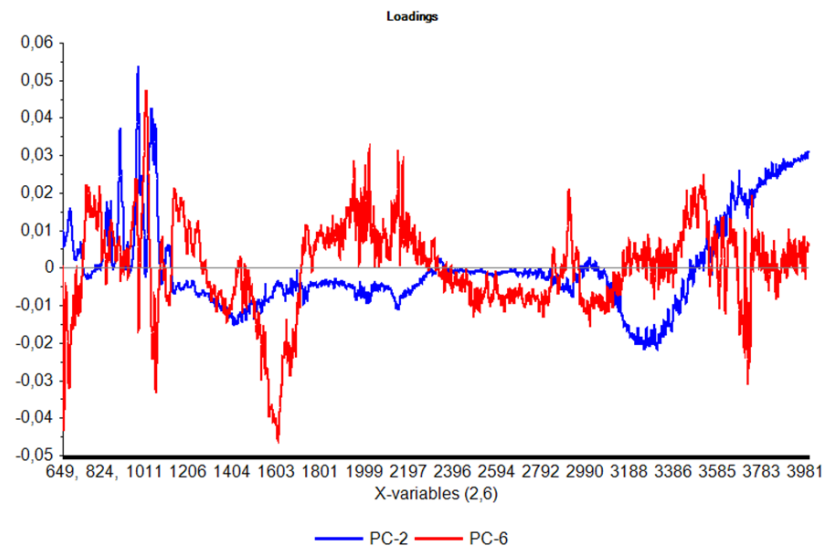

Figure 4. Loadings of SNV Spectra of FT-IR

\subsection{Partial Least Squares Regression for prediction of adulteration concentration}

Samples with all adulteration concentration as in Table 1 are used in building calibration and prediction models using the PLSR method. By using original spectra and several spectra pre-processing methods, the accuracy of the calibration model is evaluated based on a high coefficient determination of calibration $\left(\mathrm{Rc}^{2}\right)$ and low root mean standard error of calibration (RMSEC) as shown in Table 2. It can be seen in Table 2, applying pre -processing methods improve the performance of the models in which $\mathrm{Rc}^{2}$ increases and RMSEC decreases. The best PLSR calibration model with $\mathrm{Rc}^{2}$ of 0.94 and RMSEC of $8 \%$ is obtained by applying the MSC method. The model is able to predict coconut sugar

adulteration in palm sugar with $\mathrm{Rp}^{2}$ of 0.89 and root mean square error of prediction (RMSEP) of $10.68 \%$.

Table 2. Calibration and prediction results by using original and pre-processing spectra at the wavelength of $4000-650 \mathrm{~cm}^{-1}$

\begin{tabular}{ccccccc}
\hline \multirow{2}{*}{ Method } & \multicolumn{3}{c}{ Calibration } & \multicolumn{3}{c}{ Prediction } \\
\cline { 2 - 7 } & $\mathrm{N}$ & $\mathrm{Rc}^{2}$ & RMSEC (\%) & $\mathrm{N}$ & $\mathrm{Rp}^{2}$ & RMSEP (\%) \\
\hline Original & 73 & 0.87 & 11.41 & 37 & 0.84 & 12.34 \\
Normalize & 73 & 0.94 & 8.25 & 37 & 0.84 & 12.38 \\
SNV & 73 & 0.94 & 8.01 & 37 & 0.89 & 10.70 \\
MSC & 73 & 0.94 & 8.00 & 37 & 0.89 & 10.68 \\
Baseline & 73 & 0.89 & 10.31 & 37 & 0.79 & 14.04 \\
\hline
\end{tabular}

$\mathrm{N}$ : number of samples, SNV: Standard Normal Variate, MSC: Multiplicative Scatter Correction

The PLSR loadings or regression coefficients are used to determine which bands highly significant in developing a calibration model for predicting coconut sugar adulteration in palm sugar as illustrated in Figure 5. Several distinct peaks which might be related to calibration model observed at 850, 994, 1024, 1125, $1430,1613,1684,1734,2026,2941,3565$, and $3628 \mathrm{~cm}^{-}$

1 . Some of those wavelengths agree with wavelengths assigned to sucrose at 850 and $1124 \mathrm{~cm}^{-1}$, fructose at 978 $\mathrm{cm}^{-1}$, glucose at $1121 \mathrm{~cm}^{-1}$, saccharine at 1595 and 1698 $\mathrm{cm}^{-1}$ found by (Guven et al., 2019). (Anjos et al., 2015) reported wavelengths at $1500-900 \mathrm{~cm}^{-1}$ were contributed by sucrose, glucose, and fructose in honey.

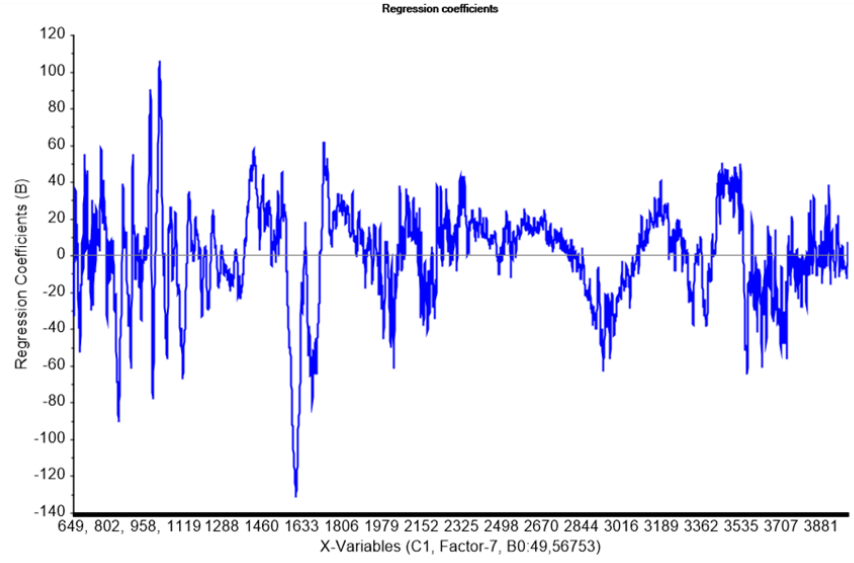

Figure 5. Regression coefficients of PLSR model using MSC Pre-processing Spectra for predicting level of coconut sugar adulteration in palm sugar 


\section{Conclusion}

This research studied the potential of FT-IR spectroscopy to detect adulteration of coconut sugar in palm sugar at various concentrations. By using MSC preprocessing spectra to develop the PLSR model, the calibration model results in $\mathrm{Rc}^{2}$ and RMSEC of 0.94 and $8 \%$. When applied to prediction data sets, the model resulted in $\mathrm{Rp}^{2}$ of 0.89 and RMSEP of $10.68 \%$. Those results indicated that the PLSR model can be used in food authentication.

\section{Conflict of interest}

The authors declare no conflict of interest.

\section{Acknowledgment}

Great appreciation is delivered to the Faculty of Agricultural Technology Universitas Gadjah Mada for financial support under Hibah Penelitian Inovatif 2019 and Mey Catur Alfiani (LPPT UGM) for her assistance in finishing this work.

\section{References}

Amanah, H.Z., Joshi, R., Masithoh, R.E., Choung, M.G., Kim, K.H., Kim, G. and Cho, B.K. (2020). Nondestructive measurement of anthocyanin in intact soybean seed using FT NIR and FT IR spectroscopy. Infrared Physics and Technology, 111, 103477. j.infrared.2020.103477

Anjos, O., Graça, M., Contreras, P. and Antunes, P. (2015). Application of FTIR-ATR spectroscopy to the quantification of sugar in honey. Food Chemistry, 169, 218-223. https://doi.org/10.1016/ j.foodchem.2014.07.138

Asghar, M.T., Yusof, Y.A., Mokhtar, M.N., Ya'acob, M.E., Mohd.Ghazali, H., Chang, L.S. and Manaf, Y. N. (2020). Coconut (Cocos nucifera L.) sap as a potential source of sugar: Antioxidant and nutritional properties. Food Science and Nutrition, 8(4), 1777 1787. https://doi.org/10.1002/fsn3.1191

Bahrami, M.E., Honarvar, M., Ansari, K. and Jamshidi, B. (2020). Measurement of quality parameters of sugar beet juices using near-infrared spectroscopy and chemometrics. Journal of Food Engineering, 271, $\quad 109775$. j.jfoodeng.2019.109775

Bergana, M.M., Adams, K.M., Harnly, J., Moore, J.C. and Xie, Z. (2019). Non-targeted detection of milk powder adulteration by $1 \mathrm{H}$ NMR spectroscopy and conformity index analysis. Journal of Food Composition and Analysis, 78, 49-58. https:// doi.org/10.1016/j.jfca.2019.01.016

Cuadros-Rodríguez, L., Ruiz-Samblás, C., ValverdeSom, L., Pérez-Castaño, E. and González-Casado, A. (2016). Chromatographic fingerprinting: An innovative approach for food "identitation" and food authentication - A tutorial. Analytica Chimica Acta, 909, 9-23. https://doi.org/10.1016/j.aca.2015.12.042

De Girolamo, A., Arroyo, M.C., Cervellieri, S., Cortese, M., Pascale, M., Logrieco, A.F. and Lippolis, V. (2020). Detection of durum wheat pasta adulteration with common wheat by infrared spectroscopy and chemometrics: A case study. LWT, 127, 109368. https://doi.org/10.1016/j.lwt.2020.109368

Direktorat Jenderal Pengembangan Ekspor Nasional. (2017, June). Peluang ekspor gula semut. Warta Ekspor. Retrieved from http://djpen.kemendag.go.id/ app_frontend/admin/docs/

publication/9501519022481.pdf. [In Bahasa Indonesia].

Domingues, D.S., Pauli, E.D., De Abreu, J.E.M., Massura, F.W., Cristiano, V., Santos, M.J. and Nixdorf, S.L. (2014). Detection of roasted and ground coffee adulteration by HPLC by amperometric and by post-column derivatization UV -Vis detection. Food Chemistry, 146, 353-362. https://doi.org/10.1016/j.foodchem.2013.09.066

Guven, B., Velioglu, S.D. and Boyaci, I.H. (2019). Rapid identification of some sweeteners and sugars by attenuated total reflectance-fourier transform infrared (ATR-FTIR), near-infrared (NIR) and raman spectroscopy. GIDA the Journal of Food, 44 (2), 274-290.

Lohumi, S., Lee, S., Lee, H. and Cho, B.K. (2015). A review of vibrational spectroscopic techniques for the detection of food authenticity and adulteration. Trends in Food Science and Technology, 46(1), 8598.https://doi.org/10.1016/j.tifs.2015.08.003

Lohumi, S., Lee, S., Lee, W.-H., Kim, M.S., Mo, C., Bae, H. and Cho, B.K. (2014). Detection of starch adulteration in onion powder by FT-NIR and FT-IR spectroscopy. Journal of Agricultural and Food Chemistry, 62, 9246-9251. https://doi.org/10.1021/ jf500574m

Masithoh, R.E., Amanah, H.Z. and Cho, B.K. (2020). Application of Fourier Transform Near-Infrared (FTNIR) and Fourier Transform Infrared (FT-IR) spectroscopy coupled with wavelength selection for fast discrimination of similar color of tuber flours. Indonesian Journal of Chemistry, 20(3), 680. https:// doi.org/10.22146/ijc.48092

Merr, W. and Haagen, A. (2014). Arenga pinnata (Wurmb) Merr. Promising Source of Bioethanol and 
Sugar with Low Glycemic Index. Online Report. https://doi.org/10.13140/RG.2.2.36701.36325

Musingarabwi, D.M., Nieuwoudt, H.H., Young, P.R., Eyéghè-Bickong, H.A. and Vivier, M.A. (2016). A rapid qualitative and quantitative evaluation of grape berries at various stages of development using Fourier-transform infrared spectroscopy and multivariate data analysis. Food Chemistry, 190, 253 -262 . https://doi.org/10.1016/ j.foodchem.2015.05.080

Srikaeo, K., Sangkhiaw, J. and Likittrakulwong, W. (2019). Productions and functional properties of palm sugars. Walailak Journal of Science and Technology, 16(11), 897-907. https:// doi.org/10.14456/vol17iss2pp

Szymańska, E., Gerretzen, J., Engel, J., Geurts, B., Blanchet, L. and Buydens, L.M.C. (2015). Chemometrics and qualitative analysis have a vibrant relationship. TrAC - Trends in Analytical Chemistry, 69, 34-51. https://doi.org/10.1016/ j.trac.2015.02.015

Wilde, A.S., Haughey, S.A., Galvin-King, P. and Elliott, C.T. (2019). The feasibility of applying NIR and FTIR fingerprinting to detect adulteration in black pepper. Food Control, 100, 1-7. https:// doi.org/10.1016/j.foodcont.2018.12.039

Zhou, W., Guo, P., Chen, J. and Lei, Y. (2020). A rapid analytical method for the quantitative determination of the sugar in acarbose fermentation by infrared spectroscopy and chemometrics. Spectrochimica Acta Part A: Molecular and Biomolecular Spectroscopy, 240, 118571. https://doi.org/10.1016/ j.saa.2020.118571 